\section{FRI0074 FACTORS ASSOCIATED WITH THE DEVELOPEMENT OF SEVERE RESPIRATORY INFECTIONS IN PATIENTS WITH RHEUMATOID ARTHRITISINCLUDED IN A VACCINATION PROGRAM}

L.C. Domínguez Casas ${ }^{1}$, P. Rodriguez-Cundin², V. Calvo-Río', N. VegasRevenga ${ }^{1}$, V. Portilla', F. Antolin ${ }^{2}$, M. Rebollo-Rodrigo ${ }^{2}$, A. Corrales ${ }^{1}$, N. PalmouFontana ${ }^{1}$, D. Prieto-Peña ${ }^{1}$, M. Calderón Goercke ${ }^{1}$, R. Blanco ${ }^{1}$, M. Gonzalez-Gay' ${ }^{1}$ Rheumatology; ${ }^{2}$ Preventive Medicine, HUMV, Santander, Spain

Background: Rheumatoid arthritis (RA) patients are at increased risk of severe infections. Besides the disease itself, the immunosuppressive treatment appears to play an important role in the risk of infections. Vaccination programs are designed to decrease the risk of infections in these patients.

Objectives: Our aim was to assess the incidence of severe respiratory infections in patients with RA and to determine the underlying risk factors for the development of these complications.

Methods: Retrospective study of 401 patients diagnosed with RA who were invited to participate in a vaccination program from October 2011 to October 2016. The follow-up was made until June 2017 with a minimum follow-up period of 8 months and maximum of 5.5 years.

Information on severe respiratory infection episodes was retrieved from the hospital medical records. Serious infections were defined as those that required hospitalisation or at least one dose of intravenous antibiotic treatment at the emergency room.

Only 7 patients refused vaccination (2\%). Information was not obtained in 4 of the remaining 394 patients. Therefore, these 4 patients were not included in the assessment.

Results: 390 patients $(307+/ 83 \precsim)$ average age $61.28 \pm 12.9$ years were vaccinated a followed-up. The main features at the time of vaccination were: median disease duration (4 years), positive rheumatoid factor (56.7\%), subcutaneous nodules $(4.9 \%)$, erosive arthritis (36.9\%), pulmonary fibrosis (3.8\%), Sjögren syndrome $(5.1 \%)$ other extraarticular manifestations (14.6\%) and rheumatoid vasculitis $(5.6 \%)$. Most patients had received immunosuppressive drugs before the vaccination program. The most frequently used were systemic corticosteroids $(n=228)$, methotrexate $(n=362)$ and biologic agents $(40.3 \%)$.

During the follow-up, 42 patients (10.7\%) had required hospital admissions due to infections, 17 of them were severe respiratory infections $(4.35 \%)$ The remaining 25 admissions were in the setting of urinary tract infections $(n=12)$, intraabdominal infections $(n=7)$, skin and soft tissues $(n=12)$ and articular $(n=1)$. Also 12 of these patients had a zoster herpes.

The presence of anti-citrullinated protein antibodies (ACPA) was associated with an increased frequency of admissions due to these infections. It was also the case for the presence of a history of biologic therapy prior to vaccination. No association of severe respiratory infection with rheumatoid factor, erosions or pulmonary fibrosis was found. (table 1).

Abstract FRI0074 - Table 1

\begin{tabular}{|c|c|c|c|c|}
\hline $\begin{array}{l}\text { Admission for severe } \\
\text { respiratory infections }\end{array}$ & $\begin{array}{l}\text { Crude OR } \\
(\mathrm{Cl} 95 \%)\end{array}$ & $p$ & $\begin{array}{l}\text { Adjusted OR* } \\
\text { (Cl95\%) }\end{array}$ & $p$ \\
\hline RF positivity & $2.13(0.67-6.83)$ & 0.2011 & $2.26(0.69-7.84)$ & 0.1799 \\
\hline ACPA positivity & $3.73(1.04-13.43)$ & 0.0441 & $4.49(1.2-16.83)$ & 0.0259 \\
\hline Erosions & $2(0,71-5.64)$ & 0.1898 & $2.16(0.75-6.25)$ & 0.1573 \\
\hline $\begin{array}{l}\text { Rheumatoid } \\
\text { vasculitis }\end{array}$ & $1.48(0.40-5.42)$ & 0.5527 & $1.38(0.37-5.22)$ & 0.6336 \\
\hline Pulmonary fibrosis & $4.27(0.87-20.91)$ & 0.2932 & $2.45(0.46-13.05)$ & 0.2932 \\
\hline $\begin{array}{l}\begin{array}{l}\text { Biologic treatment } \\
\text { before vaccination }\end{array} \\
\end{array}$ & $3.02(1.01-9.02)$ & 0.0476 & $2.61(0.85-8.07)$ & 0.0947 \\
\hline
\end{tabular}

*adjusted by age and sex

Conclusions: Vaccinated patients with RA present a low incidence of severe respiratory infections. Positivity for ACPA and the use of biologics prior to vaccination are associated with increased risk of severe respiratory infections in these patients. Therefore, vaccination should be performed prior to the onset of biologic treatment.

Disclosure of Interest: None declared

DOI: 10.1136/annrheumdis-2018-eular.7393

\section{FRI0075 \\ RISK OF HEPATITIS B INFECTION REACTIVATION IN RHEUMATIC DISEASES PATIENTS TREATED WITH ANTI-CD20 THERAPY}

M. Fornaro ${ }^{1}$, G. Lopalco ${ }^{1}$, V. Venerito ${ }^{1}$, M. Barone ${ }^{2}$, L. Cantarini ${ }^{3}$, C. Fabiani ${ }^{4}$, G. Emmi ${ }^{5}$, E. Silvestri ${ }^{5}$, G. Lapadula ${ }^{1}$, F. Iannone ${ }^{1} .{ }^{1}$ Rheumatology Unit; Department of Emergency and Organs Transplantation (DETO), University of Bari; ${ }^{2}$ Section of Gastroenterology, Department of Emergency and Organ Transplantation, University "Aldo Moro", Piazza Giulio Cesare, Bari 70124, Bari; ${ }^{3}$ Rheumatology Unit Policlinico "Le Scotte", University of Siena, Siena; ${ }^{4}$ Department of Ophthalmology, Humanitas Clinical and Research Center, Rozzano (Milan); ${ }^{5}$ Department of Experimental and Clinical Medicine, University of Florence, Firenze, Italy

Background: It has been widely established that the risk of hepatitis $B$ reactivation is high in haematological patients receiving ANTI-CD20 therapy. For these patients the use of prophylaxis with antiretroviral drugs is recommended, and the same approach is also advocated in patients affected with rheumatic diseases, although the real risk seems to be lower.

Objectives: To evaluate the risk of HBV infection reactivation in patients with rheumatic diseases undergoing treatment with ANTI-CD20 therapy.

Methods: Retrieved data including demographical, therapeutic and clinical features as well as serological data were collected in 92 patients with different rheumatic diseases who underwent treatment with ANTI-CD20 from January 2009 to December 2016. Occult HBV infection at baseline (HBsAg negative, anti-HBcAg positive with or without anti-HBsAg and undetectable HBV-DNA) was observed in 25 patients (18 rheumatoid arthritis, 4 vasculitis, 2 systemic sclerosis and 1 dermatomyositis), none of them was treated with antiretroviral prophylaxis. HBVDNA value was recorded at least every year, whereas $\mathrm{HBsAg}$ together with antiHBsAg every six months and ALT every three months.

Results: During the whole observation period (mean time $39.28 \pm 26.6$ months) none of the 25 patients (mean age $58.64 \pm 8.58$ years; $68 \%$ women) had hepatitis B reactivation or HBsAg seroreversion. During the evaluated period 2 patients dropped out therapy, 1 stopped treatment for adverse event and 1 for ineffectiveness. After 70 months of therapy 1 patient presented low fluctuation of HBV-DNA title $(13 \mathrm{IU} / \mathrm{ml})$, that spontaneously returned negative after 3 months without therapeutic changes. In addition 1 patients shown an ALT increase unrelated to HBV reactivation.

Conclusions: In line with previous data, our experience suggests that the risk of hepatitis $B$ reactivation in rheumatic patients undergoing treatment with ANTICD20 combined with SDMARD is very low. The regular monitoring of transaminases and hepatitis markers (HBsAg, antiHBsAg and HBV-DNA) during treatment has to be preferred to universal prophylaxis.

Disclosure of Interest: None declared

DOI: 10.1136/annrheumdis-2018-eular.6987

\section{FRI0076 \\ CHRONIC WIDESPREAD PAIN IN PATIENTS WITH RHEUMATOID ARTHRITIS: A SEVEN YEAR FOLLOW-UP OF PAIN DISTRIBUTION AND FACTORS FOR IMPROVEMENT}

M.L. Andersson ${ }^{1}$, B. Svensson ${ }^{1}$, S. Bergman ${ }^{2}$, on behalf of the BARFOTstudy group. ${ }^{1}$ Department of Clinical Sciences, Section of Rheumatology, Lund University, Lund; ${ }^{2}$ Primary Health Care Unit, Department of Public Health and Community Medicine, Institute of Medicine, the Sahlgrenska Academy, University of Gothenburg, Gothenburg, Sweden

Background: The knowledge of chronic widespread pain and factors associated to improvement of pain in patients with RA is sparse, in particular regarding longitudinal studies.

Objectives: To describe the change of pain distribution reports over time and to identify factors that predict improvement from chronic widespread pain in patients with RA.

Methods: Two postal questionnaires were sent out to patients included in the BARFOT (Better anti-rheumatic pharmacotherapy) study, the first in 2010 and the second in 2017. The questionnaire included a pain mannequin, NRS scales of pain, patient global assessment (PatGA) and fatigue, health assessment questionnaire $(\mathrm{HAQ})$, health related quality of life measured by $E Q-5 D$ and patient reported BMl and 28-joint count of tender (TJC) and swollen joints (SJC). The responders to both questionnaires were divided into 3 groups according to the reported pain duration and distribution at each time point- patients having no chronic pain (NCP), chronic widespread pain (CWP), and chronic regional pain (CRP). 
Results: 1525 (73\%) patients answered the pain questions in 2010 and 1046 $(68 \%)$ in 2017 . In all 950 of the patients answered the questions at both time points and were included in the study. One third (324) of the patients had reported, CWP in 2010 and 140 (43\%) of the patients with CWP in 2010 had improved in 2017. The patients, who improved, had lower BMI, $p=0.045$, less tender joint counts, $p=0.007$, less pain, $p=0.005$, less fatigue, $p<0.001$ and less painful regions, $p<0.001$, better PatGA, $p=0.002$, better $H A Q, p<0.001$ and better $E Q-5 D$, $\mathrm{p}=0.003$. Fifty-five percent of the patients who improved were treated with DMARD, compared to $52 \%$ of those not improving, the rate treated with biologics were $32 \%$ vs. $26 \%$. There were, however, no statistical significant difference in medical treatment between the groups, $\mathrm{p}=0.088$.

Age and sex adjusted logistic regression models showed an increased chance for improvement from CWP in patients with normal BMI, less TJC, pain, fatigue and tender regions and better PatGA, HAQ and EQ-5D, table 1. Biologic treatment also increased the chances to improve from CWP. The most common biologic treatment was anti-TNF treatment. Of the patients, who were treated with biologics, $86 \%$ in the group, who improved from CWP and $74 \%$ in the group, who did not improve, were treated with anti-TNF treatment. Age, gender, smoking habits, SJC and glucocorticoid treatment were not associated with improvement in the model.

Abstract FRI0076 - Table 1. A crude logistic regression model were the data were age and sex adjusted, except age, which was adjusted for sex and sex, adjusted for age.

\begin{tabular}{llll}
\hline & & OR & $95 \% \mathrm{Cl}$ \\
\hline Age 2010 & & 1.011 & $0.992-1.031$ \\
Gender & women & 0.960 & $0.542-1.702$ \\
Smoking habits 2010 & Smoker & 0.580 & $0.282-1.195$ \\
& Previous smoker & 0.793 & $0.479-1.311$ \\
BMI 2010 & $<18,5$ & 0.320 & $0.037-2.930$ \\
& $18,5-24,9$ & 2.146 & $1.121-4.106$ \\
& $25-29,9$ & 1.294 & $0.708-2.365$ \\
TJC 2010 & $<7$ & 1.798 & $1.148-2.815$ \\
SJC 2010 & $<4$ & 1.477 & $0.943-2.312$ \\
PatGA 2010 & $<4$ & 1.806 & $1.146-2.848$ \\
Pain 2010 & $<5$ & 1.836 & $1.164-2.898$ \\
Fatigue 2010 & $<6$ & 3.249 & $\mathbf{2 . 0 1 3 - 5 . 2 4 6}$ \\
EQ5D 2010 & $\geq 0.725$ & 2.092 & $1.318-3.3821$ \\
HAQ 2010 & $<0.75$ & 1.988 & $1.246-3.173$ \\
Total pain regions 2010 & $<8$ & 2.987 & $1.888-4.727$ \\
Medical treatment 2010 & DMARD & 1.779 & $0,940-3.366$ \\
& Biologics & 2.202 & $1.099-4.413$ \\
Prednisolone treatment 2010 & Pred & 0.753 & $0.448-1.265$ \\
\hline
\end{tabular}

Conclusions: Lower scores in pain related variables and fatigue, normal BMI, better physical function and health-related quality of life, and biologic treatment were associated to improvement from CWP in patients with RA. Knowledge of factors associated to improvement from CWP could be helpful when treating RA patients with CWP. More studies with focus on improvement from chronic pain in patients with RA are needed.

Disclosure of Interest: None declared

DOI: 10.1136/annrheumdis-2018-eular.2922

\section{FRI0077 HEPATITIS B VIRUS REACTIVATION IN PATIENTS WITH RHEUMATOID ARTHRITIS TREATED WITH BARICITINIB: POST-HOC ANALYSIS FROM CLINICAL TRIALS}

M. Harigai ${ }^{1}$, K. Winthrop ${ }^{2}$, T. Takeuchi ${ }^{3}$, T.-Y. Hsieh ${ }^{4}$, Y.-M. Chen ${ }^{4}$, J.S. Smolen ${ }^{5}$,

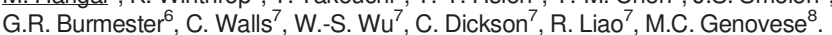
${ }^{1}$ Tokyo Women's Medical Univ, Tokyo, Japan; ${ }^{2}$ Oregon Health Sciences Univ, Portland, USA; ${ }^{3}$ Keio University, Tokyo, Japan; ${ }^{4}$ Taichung Veterans General Hospital, Taichung, Taiwan, Province of China; ${ }^{5}$ Medical Univ of Vienna, Vienna, Austria; ${ }^{6}$ Charite Universitatsmedizin Berlin, Berlin, Germany; ${ }^{7}$ Eli Lilly and Company, Indianapolis; ${ }^{8}$ Stanford Univ, Palo Alto, USA

Background: Baricitinib (BARI) is an oral selective Janus kinase (JAK)1 and JAK2 inhibitor approved in the EU, Japan, and other countries for treatment of moderately to severely active rheumatoid arthritis (RA) in adults. RA therapies may increase risk of hepatitis $B$ virus (HBV) infection ${ }^{1}$. HBV reactivation is a concern in previously infected patients (pts), including those with serologic evidence of resolution. HBV exposure is common in many Asian countries. ${ }^{2}$ Limited data exist on HBV reactivation among pts with RA treated with JAK inhibitors.

Objectives: To assess HBV reactivation in pts with RA treated with BARI during Phase $(\mathrm{Ph}) 3$ trials.
Methods: At screening, all pts were tested for HBV surface antigen (HBsAg), core antibody ( $\mathrm{HBcAb}$ ) and surface antibody (HBsAb). In Japan and elsewhere if required, pts had screening HBV DNA tests. Pts were excluded if they had 1 ) $\mathrm{HBsAg}+$, 2) $\mathrm{HBcAb}+\mathrm{HBsAb}$ - (in Japan, could enrol if HBV DNA-), or 3) HBsAb +and HBV DNA+. Routine HBV DNA monitoring was performed in Japan for pts with $\mathrm{HBcAb}+$ and/or $\mathrm{HBsAb}+$ at screening, and was later instituted globally for $\mathrm{HBcAb}+$ pts. Pts with post-baseline HBV DNA+ $(\geq 29 \mathrm{IU} / \mathrm{mL})$ were discontinued from the study and referred to a hepatologist. In select cases, investigators continued study drug following a HBV DNA +test in consultation with the sponsor and in accordance with HBV management guidelines. Data were integrated from $4 \mathrm{com}-$ pleted $\mathrm{Ph} 3$ trials and 1 ongoing long-term extension (LTE) (data to April 2017). Results: Of 2890 pts with $\geq 1$ dose of BARI (6993 pt-years exposure), 269 pts had baseline serology suggestive of prior infection ( $\mathrm{HBcAb}+/ \mathrm{HBsAb+}, \mathrm{n}=255$ $\mathrm{HBCAb+/HBsAb-,} n=14$ ) (figure 1). Post-baseline HBV DNA tests were performed for 290 pts (including some pts without a baseline HBV DNA result). After BARI initiation, 7 of 201 pts (3\%) with $\mathrm{HBcAb}+/ \mathrm{HBsAb}+$ at baseline had quantifiable HBV DNA +levels ( $>29 \mathrm{IU} / \mathrm{mL}$; median 256, range 31-1547 IU/mL). An additional 23 (11\%) had qualitative HBV DNA +results below the lower limit of detection (LLD) ( $<29 \mathrm{IU} / \mathrm{mL}$ ). Of these $30 \mathrm{HBcAb}+/ \mathrm{HBsAb}+$ pts with HBV DNA +tests post-baseline, 22 had HBV DNA- tests at baseline. Among 14 pts with $\mathrm{HBcAB}+/ \mathrm{HBs} A b-$, all had HBV DNA- tests at baseline; repeat HBV DNA test results post-baseline were quantifiable (1 at $36 \mathrm{IU} / \mathrm{mL}$ ), below the LLD, ${ }^{1}$ and undetectable. ${ }^{12}$ Of pts with quantifiable HBV DNA, adverse events (AE) of detectable HBV DNA resulted in discontinuation of 4 of 8 pts of whom 3 received antivirals. 4 of 8 pts continued BARI in the LTE and have not received antivirals. All pts with quantifiable HBV DNA had alanine transaminase (ALT) or aspartate transaminase (AST) within normal limits, and none had an investigator-reported AE of hepatitis.

HBV serology and DNA detectability in patients treated with baricitinib in Phase 3 trials

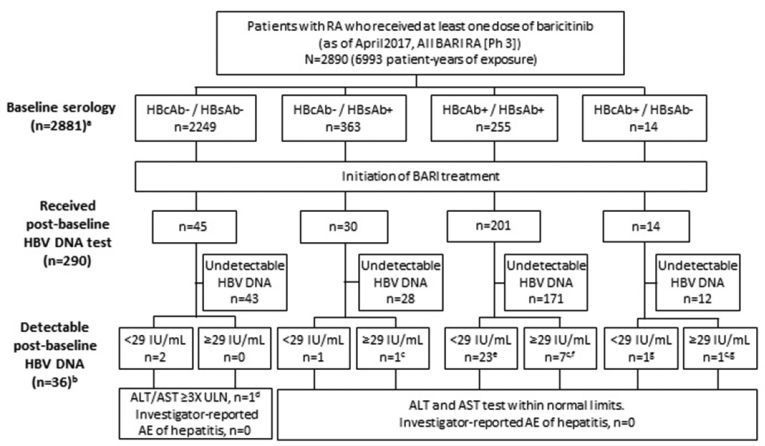

"Total number of patients with baseline serology is $n=2881$ due to missing dota for 9 patients $(8$ missing surfoceanthody

Patients with detectable post-basel ine HBV DNA were from China (11), Japan (9), Taiwan (6), Israel (2), Greece (2), Russia (2). United States (2), Argentina (1), and South Korea (1).

Nine patients had quantifiable HBV DNA levels of $31,36,60,76,92,256,257,869$, and $1547 \mathrm{IU} / \mathrm{m}$

Patient with ALT/AST $23 \times U L N$ was discontinued from study due to abnormal liver function test. Patient had a single WUIN and $<2$ XULN, respectively. (5). BBaseline HBV DNA not detected. Abbreviations: AE=adverse event, ALT=alanine transaminase, AST=aspartate transaminase, BARI=baricitinib, $H B C A b=h$ hepatitis B virus core antibody, HBsAb=hepatitis B virus surface antibody, $H B V=h e p a t i t i s B$ virus,

Abstract FRI0077 - Figure 1. HBV serology and DNA detectability in patients treated with baricitinib in Phase 3 trials

Conclusions: Approximately $12 \%$ of BARI-treated pts with prior HBV infection later tested HBV DNA+ (3\% were above the LLD), although no pts developed clinical evidence of hepatitis and in most cases antiviral therapy was not used.

\section{REFERENCES:}

[1] Chen MH, et al. J Infect Dis 2017;215(4):566-73.

[2] Chen YM, et al. JMII 2017.

Disclosure of Interest: M. Harigai Grant/research support from: BristolMyers Squibb K.K., Eisai Co., Ltd., Ono Pharmaceuticals, and Takeda Pharmaceutical Co., Ltd, Consultant for: Eli Lilly and Company, K. Winthrop Grant/research support from: Pfizer, BMS, Consultant for: Pfizer, UCB, Abbvie, Eli Lilly and Company, Amgen, BMS, T. Takeuchi: None declared, T.-Y. Hsieh: None declared, Y.-M. Chen: None declared, J. Smolen Grant/research support from: AbbVie, Janssen, Eli Lilly and Company, MSD, Pfizer, Roche, Consultant for: AbbVie, Amgen, 